\title{
Perturbed Ishikawa-hybrid quasi-proximal point algorithm with accretive mappings for a fuzzy system
}

\author{
Hong Gang Li ${ }^{1 *}$, Dong Qiu', Ji Ming Zheng ${ }^{1}$ and Mao Ming Jin²
}

"Correspondence: lihg12@126.com ${ }^{1}$ Institute of Applied Mathematics Research, Chongqing University of Posts and Telecommunications, Chongqing, 400065, China

Full list of author information is available at the end of the article

\begin{abstract}
A new class of fuzzy general nonlinear set-valued mixed quasi-variational inclusions frameworks for a perturbed Ishikawa-hybrid quasi-proximal point algorithm using the notion of $(A, \eta)$-accretive is developed. Convergence analysis for the algorithm of solving a fuzzy nonlinear set-valued inclusions problem and existence analysis of a solution for the problem is explored along with some results on the resolvent operator corresponding to an $(A, \eta)$-accretive mapping due to Lan et al. The result that the sequence $\left\{x_{n}\right\}_{n=1}^{\infty}$ generated by the perturbed Ishikawa-hybrid quasi-proximal point algorithm converges linearly to a solution of the fuzzy general nonlinear set-valued mixed quasi-variational inclusions with the convergence rate $\varepsilon$ is proved. MSC: 49J40; 47H06
\end{abstract}

Keywords: perturbed; Ishikawa-hybrid quasi-proximal point algorithm; FGNSVMQ variational inclusions; $(A, \eta)$-accretive mappings; resolvent operator; convergence

\section{Introduction}

The set-valued inclusions problem, which was introduced and discussed by Bella [1], Huang et al. [2] and Jeong [3], is a useful extension of the mathematics analysis. And the variational inclusion (inequality) is an important context in the set-valued inclusions problem. It provides us with a unified, natural, novel, innovative and general technique to study a wide class of problems arising in different branches of mathematical and engineering sciences. Various variational inclusions have been intensively studied in recent years. Ding [4], Verma [5], Huang [6], Fang and Huang [7], Lan et al. [8], Fang et al. [9], Zhang et al. [10] introduced the concepts of $\eta$-subdifferential operators, maximal $\eta$-monotone operators, $H$-monotone operators, $A$-monotone operators, $(H, \eta)$-monotone operators, $(A, \eta)$ accretive mappings, $(G, \eta)$-monotone operators and defined resolvent operators associated with them, respectively. Moreover, by using the resolvent operator technique, many authors constructed some approximation algorithms for some nonlinear variational inclusions in Hilbert spaces or Banach spaces. In 2008, Li [11] studied the existence of solutions and the stability of a perturbed Ishikawa iterative algorithm for nonlinear mixed quasi-variational inclusions involving $(A, \eta)$-accretive mappings in Banach spaces by using the resolvent operator technique.

On the other hand, in many scientific and engineering applications, the fuzzy set concept and the variational inequalities with fuzzy mappings play an important role. The fuzziness

2013 Li et al: licensee Springer. This is an Open Access article distributed under the terms of the Creative Commons Attribution License (http://creativecommons.org/licenses/by/2.0), which permits unrestricted use, distribution, and reproduction in any medium, provided the original work is properly cited. 
appears when we need to perform, on manifold, calculations with imprecision variables. The concept of fuzzy sets was introduced initially by Zadeh [12] in 1965. Since then, to use this concept in topology and analysis, many authors have expansively developed the theory of fuzzy sets and application [13, 14]. Various concepts of fuzzy metrics on an ordinary set were considered in $[15,16]$, and many authors studied fixed point theory for ordinary mappings in such fuzzy metric spaces [17-21]. A number of metrics are used on the subspaces of fuzzy sets. The sendograph metric $[22,23]$ and the d1-metric induced by the Hausdorff metric $[24,25]$ were studied most frequently. Some attention was also given to Lp-type metrics [26, 27]. These results have a very important application in quantum particle physics, particularly in connection with both string and e1-theory, which were given and studied by El-Naschie [28, 29].

From 1989, Chang and Zhu [30] introduced and investigated a class of variational inequalities for fuzzy mappings. Afterwards, Chang and Huang [31], Ding and Jong [32], Jin [33], Li [34] and others studied several kinds of variational inequalities (inclusions) for fuzzy mappings.

Recently, Verma has developed a hybrid version of the Eckstein-Bertsekas [35] proximal point algorithm, introduced the algorithm based on the $(A, \eta)$-maximal monotonicity framework [36] and studied convergence of the algorithm. The author showed the general nonlinear set-valued inclusions problem based on an $(A, \eta)$-accretive framework and suggested and discussed an Ishikawa-hybrid proximal point algorithm for solving the inclusions problem. On the other hand, from 1989, the generalized nonlinear quasi-variational inequalities (inclusions) with fuzzy mappings have been studied widely by a number of authors, who have more and more achievements [17-37], and we refer to [1-56] and references contained therein.

Inspired and motivated by recent research work in this field, in this paper, a fuzzy general nonlinear set-valued mixed quasi-variational inclusions framework for a perturbed Ishikawa-hybrid quasi-proximal point algorithm using the notion of $(A, \eta)$-accretive is developed. Convergence analysis for the algorithm of solving a fuzzy nonlinear set-valued inclusions problem and existence analysis of a solution for the problem are explored along with some results on the resolvent operator corresponding to an $(A, \eta)$-accretive mapping due to Lan et al. [8]. The result that the sequence $\left\{x_{n}\right\}_{n=1}^{\infty}$ generated by the perturbed Ishikawa-hybrid quasi-proximal point algorithm converges linearly to a solution of the fuzzy general nonlinear set-valued mixed quasi-variational inclusions with the convergence rate $\varepsilon$ is proved.

\section{Preliminaries}

Let $X$ be a real Banach space with the dual space $X^{*},\langle\cdot, \cdot\rangle$ be the dual pair between $X$ and $X^{*}, 2^{X}$ denote the family of all the nonempty subsets of $X$, and $\mathrm{CB}(X)$ denote the family of all nonempty closed bounded subsets of $X$. The generalized duality mapping $J_{q}: X \rightarrow 2^{X^{*}}$ is defined by

$$
J_{q}(x)=\left\{f^{*} \in X^{*}:\left\langle x, f^{*}\right\rangle=\|x\|^{q},\left\|f^{*}\right\|=\|x\|^{q-1}\right\}, \quad \forall x \in X,
$$

where $q>1$ is a constant.

The modulus of smoothness of $X$ is the function $\rho_{X}:[0, \infty) \rightarrow[0, \infty)$ defined by

$$
\rho_{X}(t)=\sup \left\{\frac{1}{2}(\|x+y\|+\|x-y\|)-1:\|x\| \leq 1,\|y\| \leq t\right\} .
$$


A Banach space $X$ is called uniformly smooth if

$$
\lim _{t \rightarrow 0} \frac{\rho_{X}(t)}{t}=0
$$

$\mathrm{X}$ is called q-uniformly smooth if there exists a constant $c>0$ such that

$$
\rho_{X}(t) \leq c t^{q} \quad(q>1) .
$$

Remark 2.1 In particular, $J_{2}$ is the usual normalized duality mapping, and $J_{q}(x)=$ $\|x\|^{q-2} J_{2}(x)$ (for all $x \neq 0$ ). If $X^{*}$ is strictly convex [41], or $X$ is a uniformly smooth Banach space, then $J_{q}$ is single-valued. In what follows, we always denote the single-valued generalized duality mapping by $J_{q}$ in a real uniformly smooth Banach space $X$ unless otherwise stated.

Let us recall the following results and concepts.

Definition 2.2 A single-valued mapping $\eta: X \times X \rightarrow X$ is said to be $\tau$-Lipschitz continuous if there exists a constant $\tau>0$ such that

$$
\|\eta(x, y)\| \leq \tau\|x-y\|, \quad \forall x, y \in X .
$$

Definition 2.3 A single-valued mapping $A: X \rightarrow X$ is said to be

(i) accretive if

$$
\left\langle A\left(x_{1}\right)-A\left(x_{2}\right), J_{q}\left(x_{1}-x_{2}\right)\right\rangle \geq 0, \quad \forall x_{1}, x_{2} \in X
$$

(ii) strictly accretive if $A$ is accretive and $\left\langle A\left(x_{1}\right)-A\left(x_{2}\right), J_{q}\left(x_{1}-x_{2}\right)\right\rangle=0$ if and only if $x_{1}=x_{2} \forall x_{1}, x_{2} \in X$

(iii) $r$-strongly $\eta$-accretive if there exists a constant $r>0$ such that

$$
\left\langle A\left(x_{1}\right)-A\left(x_{2}\right), J_{q}\left(\eta\left(x_{1}, x_{2}\right)\right)\right\rangle \geq r\left\|x_{1}-x_{2}\right\|^{q}, \quad \forall x_{1}, x_{2} \in X
$$

(iv) $\alpha$-Lipschitz continuous if there exists a constant $\alpha>0$ such that

$$
\left\|A\left(x_{1}\right)-A\left(x_{2}\right)\right\| \leq \alpha\left\|x_{1}-x_{2}\right\|, \quad \forall x_{1}, x_{2} \in X .
$$

(v) A single-valued mapping $F: X \times X \rightarrow X$ is said to be $(\mu, v)$-Lipschitz continuous if there exist constants $\mu, v>0$ such that

$$
\left\|F\left(x_{1}, y_{1}\right)-F\left(x_{2}, y_{2}\right)\right\| \leq \mu\left\|x_{1}-x_{2}\right\|+v\left\|y_{1}-y_{2}\right\| \quad \forall x_{i}, y_{i} \in X, i=1,2 .
$$

(vi) Let $A, g: X \rightarrow X$ be single-valued mappings, $S: X \rightarrow 2^{X}$ be a set-valued mapping. $g$ is said to be $(\psi, \kappa)$-S-relaxed cocoercive with respect to $A$ mapping, if there exist two constants $\psi, \kappa>0$ such that for any $x_{i} \in X$, the following holds:

$$
\begin{aligned}
& \left\langle A\left(u_{1}\right)-A\left(u_{2}\right), J_{q}\left(g\left(x_{1}\right)-g\left(x_{2}\right)\right)\right\rangle \\
& \quad \geq \psi\left\|x_{1}-x_{2}\right\|^{q}-\kappa\left\|A\left(u_{1}\right)-A\left(u_{2}\right)\right\|^{q}, \quad \forall u_{i} \in S\left(x_{i}\right), i=1,2 .
\end{aligned}
$$


Definition 2.4 Let $A: X \rightarrow X$ and $\eta: X \times X \rightarrow X$ be single-valued mappings. A set-valued mapping $G: X \rightarrow 2^{X}$ is said to be:

(i) accretive if

$$
\left\langle u_{1}-u_{2}, J_{q}\left(x_{1}-x_{2}\right)\right| \geq 0, \quad \forall x_{1}, x_{2} \in X, u_{1} \in G\left(x_{1}\right), u_{2} \in G\left(x_{2}\right)
$$

(ii) $\eta$-accretive if

$$
\left\langle u_{1}-u_{2}, J_{q}\left(\eta\left(x_{1}, x_{2}\right)\right)\right\rangle \geq 0, \quad \forall x_{1}, x_{2} \in X, u_{1} \in G\left(x_{1}\right), u_{2} \in G\left(x_{2}\right)
$$

(iii) $r$-strongly accretive if there exists a constant $r>0$ such that

$$
\left\langle y_{1}-y_{2}, J_{q}\left(x_{1}-x_{2}\right)\right\rangle \geq r\left\|x_{1}-x_{2}\right\|^{q}, \quad \forall x_{i} \in X, y_{i} \in G\left(x_{i}\right)(i=1,2) ;
$$

(iv) $m$-relaxed $\eta$-accretive if there exists a constant $m>0$ such that

$$
\left\langle u_{1}-u_{2}, J_{q}\left(\eta\left(x_{1}, x_{2}\right)\right)\right\rangle \geq-m\left\|x_{1}-x_{2}\right\|^{q}, \quad \forall x_{1}, x_{2} \in X, u_{1} \in G\left(x_{1}\right), u_{2} \in G\left(x_{2}\right) .
$$

(v) $A$-accretive if $M$ is accretive and $(A+\rho G)(X)=X$ for all $\rho>0$;

(vi) $(A, \eta)$-accretive if $M$ is $m$-relaxed $\eta$-accretive and $(A+\rho G)(X)=X$ for all $\rho>0$.

(vii) $\mathbf{h}$-Lipschitz continuous with constants $\xi$ if

$$
\mathbf{h}\left(G\left(x_{1}\right), G\left(x_{2}\right)\right) \leq \xi\left\|x_{1}-x_{2}\right\|, \quad \forall x_{1}, x_{2} \in X,
$$

where $\mathbf{h}(\cdot, \cdot)$ is the Hausdorff metric in $\mathrm{CB}(X)$.

Based on the literature [8], we can define the resolvent operator $R_{\rho, G}^{A, \eta}$ as follows.

Definition 2.5 ([8]) Let $\eta: X \times X \rightarrow X$ be a single-valued mapping, $A: X \rightarrow X$ be a strictly $\eta$-accretive single-valued mapping and $G: X \times X \rightarrow 2^{X}$ be an $(A, \eta)$-accretive mapping. The resolvent operator $R_{\rho, G}^{A, \eta}: X \rightarrow X$ is defined by

$$
R_{\rho, G}^{A, \eta}(x)=(A+\rho G)^{-1}(x) \quad \text { for all } x \in X,
$$

where $\rho>0$ is a constant.

Remark 2.6 The $(A, \eta)$-accretive mappings are more general than the $(H, \eta)$-monotone mappings and $m$-accretive mappings in a Banach space or a Hilbert space, and the resolvent operators associated with $(A, \eta)$-accretive mappings include as special cases the corresponding resolvent operators associated with $(H, \eta)$-monotone operators, $m$-accretive mappings, $A$-monotone operators, $\eta$-subdifferential operators [3-11, 30-34].

Lemma 2.7 ([8]) Let $\eta: X \times X \rightarrow X$ be a $\tau$-Lipschitz continuous mapping, $A: X \rightarrow X$ be an $r$-strongly $\eta$-accretive mapping, and $G: X \times X \rightarrow 2^{X}$ be an $(A, \eta)$-accretive mapping. Then the generalized resolvent operator $R_{\rho, G}^{A, \eta}: X \rightarrow X$ is $\tau^{q-1} /(r-m \rho)$-Lipschitz continuous, that is,

$$
\left\|R_{\rho, G}^{A, \eta}(x)-R_{\rho, G}^{A, \eta}(y)\right\| \leq \frac{\tau^{q-1}}{r-m \rho}\|x-y\| \quad \text { for all } x, y \in X,
$$

where $\rho \in(0, r / m)$. 
In the study of characteristic inequalities in $q$-uniformly smooth Banach spaces, Xu [38] proved the following result.

Lemma 2.8 ([38]) Let $X$ be a real uniformly smooth Banach space. Then $X$ is q-uniformly smooth if and only if there exists a constant $c_{q}>0$ such that for all $x, y \in X$,

$$
\|x+y\|^{q} \leq\|x\|^{q}+q\left\langle y, J_{q}(x)\right\rangle+c_{q}\|y\|^{q} .
$$

\section{Fuzzy general nonlinear set-valued mixed quasi variational inclusions with $(A, \eta)$-accretive mappings}

Let $X$ be a real $q$-uniformly smooth Banach space with the dual space $X^{*},\langle\cdot, \cdot\rangle$ be the dual pair between $X$ and $X^{*}, 2^{X}$ denote the family of all the nonempty subsets of $X$, and $\operatorname{CB}(X)$ denote the family of all nonempty closed bounded subsets of $X$.

Let $\mathcal{F}(X)$ be a collection of all fuzzy sets over $X$. A mapping $\widehat{F}: X \rightarrow \mathcal{F}(X)$ is called a fuzzy mapping. For each $x \in X, \widehat{F}(x)$ (denote it by $\widehat{F}_{x}$ in the sequel) is a fuzzy set on $X$ and $\widehat{F}_{x}(y)$ is the membership function of $y$ in $\widehat{F}_{x}$. For $\widehat{B} \in \mathcal{F}(X), q \in[0,1]$, the set $(\widehat{B})_{q}=\{x \in X$ : $\widehat{B}(x) \geq q\}$ is called a $q$-cut set of $\widehat{B}$.

Let $C=\{1,2,3,4\}$ for any $k \in C, \widehat{S_{k}}: X \rightarrow \mathcal{F}(X)$ be a fuzzy mapping satisfying the condition $(*)$ :

there exists a function $a_{k}: X \rightarrow[0,1]$ such that for all $x \in X,\left(\widehat{S}_{x}\right)_{a_{k}(x)} \in \mathrm{CB}(X)$, where $\mathrm{CB}(X)$ denotes the family of all nonempty bounded closed subsets of $X$.

By using the fuzzy mapping $\widehat{S_{k}}$, we can define a set-valued mapping $S_{k}: X \rightarrow \mathrm{CB}(X)$ by $S_{k}(x)=\left(\widehat{S}_{x}\right)_{a_{k}(x)}$ for each $x \in X$, and $S_{k}$ is called the set-valued mapping induced by the fuzzy mapping $\widehat{S_{k}}$ for any $k \in C$ in the sequel, respectively.

Let $A, f, g: X \rightarrow X ; \eta, F: X \times X \rightarrow X$ be single-valued mappings. Let $G: X \times X \rightarrow 2^{X}$ be a set-valued $(A, \eta)$-accretive mapping and range $\left(S_{3}\right) \cap \operatorname{dom} G(\cdot, t) \neq \emptyset$ for each $t \in X$. We consider the fuzzy general nonlinear set-valued mixed quasi-variational inclusions with $(A, \eta)$-accretive mappings (FGNSVMQVI):

Find $x \in X$ and $b^{k} \in X(k \in C)$ such that $\widehat{S}_{k x}\left(b^{k}\right) \geq a_{k}(x)$ and

$$
0 \in F\left(b^{1}, f\left(b^{2}\right)\right)+G\left(b^{3}, b^{4}\right)+g(x),
$$

where problem (3.1) is called fuzzy general nonlinear set-valued mixed quasi-variational inclusions with $(A, \eta)$-accretive mappings.

If for any $k \in C, S_{k}: X \rightarrow \mathrm{CB}(X)$ is a set-valued mapping, we can define the fuzzy mapping $\widehat{S}_{k x}(u) \geq a_{k}(x): X \rightarrow \mathcal{F}(X)$ by $x \mapsto \chi_{S_{k}(x)}$, where $\chi_{S_{k}(x)}$ is the characteristic function of $\widehat{S_{k}}$. Taking $a_{k}(x)=1(k \in C)$ for all $x \in X$, problem (3.1) is equivalent to the following problem:

Find $x \in X$ and $b^{k} \in S_{k}(x)(k \in C)$ such that

$$
0 \in F\left(b^{1}, f\left(b^{2}\right)\right)+G\left(b^{3}, b^{4}\right)+g(x),
$$

which is called a new class of general nonlinear set-valued mixed quasi-variational inclusions with $(A, \eta)$-accretive mappings (GNSVMQVI). 


\section{Remark 3.1}

(1) A special case of problem (3.1) is the following:

(i) If $X$ is a Hilbert space, an $(A, \eta)$-accretive mapping $\widehat{S_{1}}=\widehat{S}, \widehat{S_{2}}=\widehat{T}, \widehat{S_{3}}=g, \widehat{S_{4}}=\widehat{G}$, $a_{1}(x)=a(x), a_{2}(x)=b(x), a_{3}(x)=c(x)$, and $F(\cdot, \cdot)=N(\cdot, \cdot)$ and $M(\cdot, \cdot)=G(\cdot, \cdot)$, then problem (3.1) becomes problem (2.1) in [53], which was studied by Li [53].

(ii) For a suitable choice of $A, f, g, \eta, F, G, \widehat{S_{k}}(k \in C)$ and the space $X$, a number of known classes of fuzzy variational inclusions and fuzzy variational inequalities in [30-32,37] can be obtained as special cases of the fuzzy general nonlinear set-valued mixed quasi-variational inclusions (3.1).

(2) A special case of problem (3.2) is the following:

(i) Comparing problem (2.2) in [55] and letting $g(x)=-u$ be a constant in $X$, $S_{1}(x)=S_{3}(x)=S_{4}(x)=Q(x)$ be single-valued mappings, $S_{2}(x)=x$ and $f=g$ and $F=N, G(\cdot)=M(\cdot, \cdot)$, then we can see that GNSVMQVI (3.2) becomes problem (2.2) in [55] as follows:

For any $u \in X$, find $x \in X$ and $y=Q(x)$ such that

$$
u \in N(y, g(x))+M(y) .
$$

(ii) If $X=X^{*}$ is a Hilbert space, $F=0$ is the zero operator in $X$,

$S_{1}(x)=S_{3}(x)=S_{4}(x)=f(x)=Q(x)=I$ are the identity operators in $X, g=0$, and $G(\cdot, \cdot)=M(\cdot)$, then problem (3.2) becomes the parametric usual variational inclusion $0 \in M(x)$ with an $(A, \eta)$-maximal monotone mapping $M$, which was studied by Verma [36].

(iii) If $X$ is a real Banach space, $Q=I$ is the identity operator in $X$, and $u=0$, then problem (3.3) becomes the parametric usual variational inclusion $u \in N(x, g(x))+M(x)$ with an $(A, \eta)$-accretive mapping, which was studied by Li [54].

Furthermore, these types of fuzzy variational inclusions and variational inclusions can enable us to study many important nonlinear problems arising in mechanics, physics, optimization and control, nonlinear programming, economics, finance, regional, structural, transportation, elasticity and applied sciences in a general and unified framework.

\section{The existence of solutions}

Now, we study the existence of solutions for problem (3.1).

Lemma 4.1 Let $X$ be a Banach space. Let $S_{k}$ be the set-valued mapping induced by the fuzzy mapping $\widehat{S_{k}}$ for any $k \in\{1,2,3,4\}$, let $\eta: X \times X \rightarrow X$ be a $\tau$-Lipschitz continuous mapping, $A: X \rightarrow X$ be an r-strongly $\eta$-accretive mapping, $F: X \times X \rightarrow X$ be a singlevalued mapping, and $G(\cdot, t): X \times X \rightarrow 2^{X}$ be an $(A, \eta)$-accretive mapping for any $t \in X$. Then the following statements are mutually equivalent:

(i) $\left(x, b^{1}, b^{2}, b^{3}, b^{4}\right) \in X^{5}$ is a solution of problem (3.1), where $\widehat{S_{k}(x)}\left(b^{k}\right) \geq a_{k}(x)$, that is, $b^{k} \in S_{k}(x)(1 \leq k \leq 4)$.

(ii) For $\left(x, b^{1}, b^{2}, b^{3}, b^{4}\right) \in X^{5}$ and any $1>\lambda>0$, the following relation holds:

$$
b^{3}=R_{\rho, G\left(b^{3}, b^{4}\right)}^{A, \eta}\left(\left(A\left(b^{3}\right)-\rho F\left(b^{1}, f\left(b^{2}\right)\right)-\rho g(x)\right)\right),
$$

where $\widehat{S_{k}(x)}\left(b^{k}\right) \geq a_{k}(x)$, that is, $b^{k} \in S_{k}(x)(1 \leq k \leq 4)$. 
(iii) For $\left(x, b^{1}, b^{2}, b^{3}, b^{4}\right) \in X^{5}$ and any $1>\lambda>0$, the following relation holds:

$$
x=(1-\lambda) x+\lambda\left(x-b^{3}+R_{\rho, G\left(b^{3}, b^{4}\right)}^{A, \eta}\left(A\left(b^{3}\right)-\rho F\left(b^{1}, f\left(b^{2}\right)\right)-\rho g(x)\right)\right),
$$

where $\rho>0$ is a constant, and $\widehat{S_{k}(x)}\left(b^{k}\right) \geq a_{k}(x)$, that is, $b^{k} \in S_{k}(x)(1 \leq k \leq 4)$.

Proof This directly follows from the definition of $R_{\rho, G\left(\cdot, b^{4}\right)^{A}}^{A, \eta}$

Theorem 4.2 Let $X$ be a q-uniformly smooth Banach space. Let $A, f, g: X \rightarrow X ; \eta, N$ : $X \times X \rightarrow X$ be single-valued mappings, and let $\eta$ be a $\tau$-Lipschitz continuous mapping, $A$ be an r-strongly $\eta$-accretive and $\alpha$-Lipschitz continuous mapping, $f$ be a $\chi$-Lipschitz continuous mapping, and $g$ be a $\varphi$-Lipschitz continuous and $(\psi, \kappa)-S_{3}$-relaxed cocoercive with respect to $A$ mapping, respectively. For $k \in\{1,2,3,4\}$, let $\widehat{S_{k}}: X \rightarrow \mathcal{F}(X)$ be a fuzzy mapping satisfying condition $(*)$ and $S_{k}: X \rightarrow \mathrm{CB}(X)$ be a set-valued mapping induced by the fuzzy mapping $\widehat{S_{k}}$, and suppose that $S_{k}$ is D-Lipschitz continuous with constants $\xi_{k}$ and that $S_{3}$ is $\gamma$-strongly accretive. Let $F: X \times X \rightarrow X$ be $(\mu, v)$-Lipschitz continuous. Let $G(\cdot, t): X \rightarrow 2^{X}$ be a set-valued $(A, \eta)$-accretive mapping for any $t \in X$ and $\operatorname{range}\left(S_{3}\right) \cap$ $\operatorname{dom} G(\cdot, t) \neq \varnothing$, and for any $x, y, z \in X$,

$$
\left\|R_{\rho, G(x, \cdot)}^{A, \eta}(z)-R_{\rho, G(y, \cdot)}^{A, \eta}(z)\right\| \leq \delta\|x-y\|
$$

If there exists a constant $\rho>0$ such that the following condition holds:

$$
\begin{aligned}
(1- & \left.\left(1+c_{q} \chi^{q}-q \gamma\right)^{\frac{1}{q}}-\delta \xi_{3}^{q}\right)(r-m \rho) \tau^{q-1} \\
& <\rho\left(\mu \xi_{1}+v \chi \xi_{2}\right)+\left(\alpha^{q} \xi_{3}^{q}+c_{q} \rho^{q} \varphi^{q}-q \rho \psi+\rho \kappa \alpha^{q} \xi_{1}^{q}\right)^{\frac{1}{q}}
\end{aligned}
$$

where $c_{q}>0$ is the same as in Lemma 2.8, and $\rho \in\left(0, \frac{r}{m}\right)$, then problem (3.1) has a solution $\left(x^{*}, b^{1 *}, b^{2 *}, b^{3 *}, b^{4 *}\right) \in X^{5}$, which $b^{k *} \in S_{k}\left(x^{*}\right)(1 \leq k \leq 4)$.

Proof For $1>\lambda>0$, define a mapping $H: X \rightarrow X$ as follows:

$$
\begin{aligned}
H(x)= & (1-\lambda) x+\lambda\left(x-b^{3}\right. \\
& \left.+R_{\rho, G\left(b^{3}, b^{4}\right)}^{A, \eta}\left(A\left(b^{3}\right)-\rho F\left(b^{1}, f\left(b^{2}\right)\right)-\rho g(x)\right)\right) \quad(\forall x \in X) .
\end{aligned}
$$

For elements $x_{i} \in X$, if for $k \in\{1,2,3,4\}$, letting $\widehat{S_{k x_{i}}}\left(b_{i}^{k}\right) \geq a_{k}\left(x_{i}\right)$ or $b_{i}^{k} \in S_{k}\left(x_{i}\right)$ and

$$
t_{i}=A\left(b_{i}^{3}\right)-\rho F\left(b_{i}^{1}, f\left(b_{i}^{2}\right)\right)-\rho g\left(x_{i}\right) \quad(i=1,2),
$$

then by (4.1), (4.2), (4.4), Lemma 2.7 and Lemma 2.8, we have

$$
\begin{aligned}
& \left\|H\left(x_{1}\right)-H\left(x_{2}\right)\right\| \\
& \quad=\left\|(1-\lambda) x_{1}+\lambda\left(x_{1}-b_{1}^{3}+R_{\rho, G\left(b_{1}^{3}, b_{1}^{4}\right)}^{A, \eta}\left(t_{1}\right)\right)-(1-\lambda) x_{2}-\lambda\left(x_{2}-b_{2}^{3}+R_{\rho, G\left(b_{2}^{3}, b_{2}^{4}\right)}^{A, \eta}\left(t_{2}\right)\right)\right\| \\
& \quad \leq(1-\lambda)\left\|x_{1}-x_{2}\right\|+\lambda\left\|x_{1}-x_{2}-\left(b_{1}^{3}-b_{2}^{3}\right)\right\|+\lambda\left\|R_{\rho, G\left(b_{1}^{3}, b_{1}^{4}\right)}^{A, \eta}\left(t_{1}\right)-R_{\rho, G\left(b_{2}^{3}, b_{2}^{4}\right)}^{A, \eta}\left(t_{2}\right)\right\| \\
& \quad \leq(1-\lambda)\left\|x_{1}-x_{2}\right\|+\lambda\left\|x_{1}-x_{2}-\left(b_{1}^{3}-b_{2}^{3}\right)\right\|
\end{aligned}
$$




$$
\begin{gathered}
+\left(\left\|R_{\rho, G\left(b_{1}^{3}, b_{1}^{4}\right)}^{A, \eta}\left(t_{1}\right)-R_{\rho, G\left(b_{1}^{3}, b_{2}^{4}\right)}^{A, \eta}\left(t_{1}\right)\right\|+\left\|R_{\rho, G\left(b_{1}^{3}, b_{2}^{4}\right)}^{A, \eta}\left(t_{1}\right)-R_{\rho, G\left(b_{2}^{3}, b_{2}^{4}\right)}^{A, \eta}\left(t_{2}\right)\right\|\right) \\
\leq(1-\lambda)\left\|x_{1}-x_{2}\right\|+\lambda\left\|x_{1}-x_{2}-\left(b_{1}^{3}-b_{2}^{3}\right)\right\|+\delta\left\|b_{1}^{3}-b_{2}^{3}\right\|+\frac{\tau^{q-1}}{r-m \rho}\left\|t_{1}-t_{2}\right\|,
\end{gathered}
$$

where

$$
\begin{aligned}
\left\|t_{1}-t_{2}\right\| & =\left\|A\left(b_{1}^{3}\right)-A\left(b_{2}^{3}\right)-\rho\left(F\left(b_{1}^{1}, f\left(b_{1}^{2}\right)\right)-F\left(b_{2}^{1}, f\left(b_{2}^{2}\right)\right)\right)-\rho\left(g\left(x_{1}\right)-g\left(x_{2}\right)\right)\right\| \\
& \leq\left\|A\left(b_{1}^{3}\right)-A\left(b_{2}^{3}\right)-\rho\left(g\left(x_{1}\right)-g\left(x_{2}\right)\right)\right\|+\rho\left\|F\left(b_{1}^{1}, f\left(b_{1}^{2}\right)\right)-F\left(b_{2}^{1}, f\left(b_{2}^{2}\right)\right)\right\| .
\end{aligned}
$$

Since $g$ is $\varphi$-Lipschitz continuous and $(\psi, \kappa)-S_{3}$-relaxed cocoercive with respect to $A$ and $A$ is $\alpha$-Lipschitz continuous, we obtain

$$
\begin{aligned}
& \left\|A\left(b_{1}^{3}\right)-A\left(b_{2}^{3}\right)-\rho\left(g\left(x_{1}\right)-g\left(x_{2}\right)\right)\right\|^{q} \\
& \quad \leq\left\|A\left(b_{1}^{3}\right)-A\left(b_{2}^{3}\right)\right\|^{q}+c_{q} \rho^{q}\left\|g\left(x_{1}\right)-g\left(x_{2}\right)\right\|^{q}-q \rho\left\langle A\left(b_{1}^{3}\right)-A\left(b_{2}^{3}\right), J_{q}\left(g\left(x_{1}\right)-g\left(x_{2}\right)\right)\right\rangle \\
& \quad \leq \alpha^{q} \xi_{3}^{q}\left\|x_{1}-x_{2}\right\|^{q}+c_{q} \rho^{q} \varphi^{q}\left\|x_{1}-x_{2}\right\|^{q}-q \rho \psi\left\|x_{1}-x_{2}\right\|^{q}+\rho \kappa\left\|A\left(b_{1}^{3}\right)-A\left(b_{2}^{3}\right)\right\|^{q} \\
& \quad \leq \alpha^{q} \xi_{3}^{q}\left\|x_{1}-x_{2}\right\|^{q}+c_{q} \rho^{q} \varphi^{q}\left\|x_{1}-x_{2}\right\|^{q}-q \rho \psi\left\|x_{1}-x_{2}\right\|^{q}+\rho \kappa \alpha^{q} \xi_{3}^{q}\left\|x_{1}-x_{2}\right\|^{q} \\
& \quad \leq\left(\alpha^{q} \xi_{3}^{q}+c_{q} \rho^{q} \varphi^{q}-q \rho \psi+\rho \kappa \alpha^{q} \xi_{1}^{q}\right)\left\|x_{1}-x_{2}\right\|^{q} .
\end{aligned}
$$

Since $F(\cdot, \cdot)$ is $(\mu, \nu)$-Lipschitz continuous and $f$ is $\chi$-Lipschitz continuous, the following holds:

$$
\begin{aligned}
& \left\|F\left(b_{1}^{1}, f\left(b_{1}^{2}\right)\right)-F\left(b_{2}^{1}, f\left(b_{2}^{2}\right)\right)\right\| \\
& \quad \leq \mu\left\|b_{1}^{1}-b_{2}^{1}\right\|+v\left\|f\left(b_{1}^{2}\right)-\left(b_{2}^{2}\right)\right\| \leq\left(\mu \xi_{1}+v \chi \xi_{2}\right)\left\|x_{1}-x_{2}\right\| .
\end{aligned}
$$

By using $\gamma$-strong accretion of $S_{3}$, we obtain

$$
\begin{aligned}
\left\|x_{1}-x_{2}-\left(b_{1}^{3}-b_{2}^{3}\right)\right\|^{q} & \leq\left\|x_{1}-x_{2}\right\|^{q}+c_{q}\left\|b_{1}^{3}-b_{2}^{3}\right\|^{q}-q\left\langle b_{1}^{3}-b_{2}^{3}, J_{q}\left(x_{1}-x_{2}\right)\right\rangle \\
& \leq\left(1+c_{q} \xi_{3}^{q}-q \gamma\right)\left\|x_{1}-x_{2}\right\|^{q} .
\end{aligned}
$$

Combining(4.5), (4.6), (4.7) and (4.8), we can get

$$
\left\|H\left(x_{1}\right)-H\left(x_{2}\right)\right\| \leq[(1-\lambda)+\lambda \theta]\left\|x_{1}-x_{2}\right\|
$$

where

$$
\begin{aligned}
\theta= & \left(1+c_{q} \chi^{q}-q \gamma\right)^{\frac{1}{q}}+\delta \xi_{3}^{q} \\
& +\frac{\tau^{q-1}}{r-m \rho}\left[\rho\left(\mu \xi_{1}+\nu \chi \xi_{2}\right)+\left(\alpha^{q} \xi_{3}^{q}+c_{q} \rho^{q} \varphi^{q}-q \rho \psi+\rho \kappa \alpha^{q} \xi_{1}^{q}\right)^{\frac{1}{q}}\right] .
\end{aligned}
$$

It follows from (4.3) and (4.9) that $H$ has a fixed point in $X$, i.e., there exists a point $x^{*} \in X$ such that

$$
x^{*}=(1-\lambda) x^{*}+\lambda\left(x^{*}-b^{3 *}+R_{\rho, G\left(b^{3 *}, b^{4 *}\right)}^{A}\left(A\left(b^{3 *}\right)-\rho F\left(b^{1 *}, b^{2 *}\right)+\rho g\left(x^{*}\right)\right)\right),
$$

where $b^{k *} \in S_{k}\left(x^{*}\right)(1 \leq k \leq 4)$. This completes the proof. 


\section{Perturbed Ishikawa-hybrid quasi-proximal point algorithm and solvability of problem (3.1)}

Based on Lemma 4.1, we develop a perturbed Ishikawa-hybrid quasi-proximal point algorithm for finding iterative sequence solving problem (3.1) as follows.

Algorithm 5.1 Let $X$ be a q-uniformly smooth Banach space, let $\widehat{S_{k}}: X \rightarrow \mathcal{F}(x)$ be a fuzzy mapping satisfying condition $(*)$ and $S_{k}: X \rightarrow \mathrm{CB}(X)$ be the set-valued mapping induced by the fuzzy mapping $\widehat{S_{k}}(1 \leq k \leq 4)$. Let $A, f, g: X \rightarrow X, \eta, F: X \times X \rightarrow X$ be single-valued mappings, and let $G: X \times X \rightarrow 2^{X}$ be such that for each fixed $t \in X, G(\cdot, t): X \rightarrow 2^{X}$ is an $(A, \eta)$-accretive mapping and range $\left(S_{3}\right) \cap \operatorname{dom} G(\cdot, t) \neq \emptyset$. Let $\left\{u_{n}\right\}_{n=0}^{\infty},\left\{v_{n}\right\}_{n=0}^{\infty},\left\{p_{n}\right\}_{n=0}^{\infty}$, $\left\{s_{n}\right\}_{n=0}^{\infty},\left\{l_{n}\right\}_{n=0}^{\infty},\left\{t_{n}\right\}_{n=0}^{\infty}$ and $\left\{\rho_{n}\right\}_{n=0}^{\infty}$ be five nonnegative sequences such that

$$
\begin{aligned}
& \lim _{n \rightarrow \infty} p_{n}=\lim _{n \rightarrow \infty} s_{n}=\lim _{n \rightarrow \infty} l_{n}=\lim _{n \rightarrow \infty} t_{n}=0, \\
& u=\limsup _{n \rightarrow \infty} u_{n}<1, \quad v=\limsup _{n \rightarrow \infty} v_{n}<1, \quad \rho_{n} \uparrow \rho \leq \infty .
\end{aligned}
$$

Step 1: For an arbitrarily initial point $x_{0} \in X$, we choose suitable $b_{x_{0}}^{k} \in S_{k}\left(x_{0}\right)(1 \leq k \leq 4)$, $z_{0} \in X, b_{z_{0}}^{3} \in S_{3}\left(z_{0}\right)$ and $b_{w_{0}}^{3} \in S_{3}\left(w_{0}\right)$, letting

$$
\left\{\begin{array}{l}
y_{0}=\left(1-v_{0}\right) x_{0}+v_{0} z_{0}+l_{0} e_{0}, \\
\left\|z_{0}-\left[x_{0}-b_{x_{0}}^{3}+R_{\rho_{0}, G\left(b_{x_{0}}^{3}, b_{x_{0}}^{4}\right)}^{A}\left(A\left(b_{x_{0}}^{3}\right)-\rho_{0} F\left(b_{x_{0}}^{1}, b_{x_{0}}^{2}\right)+\rho_{0} g\left(x_{0}\right)\right)\right]\right\| \\
\quad \leq p_{0}\left\|z_{0}-x_{0}-\left(b_{z_{0}}^{3}-b_{x_{0}}^{3}\right)\right\|, \\
x_{1}=\left(1-u_{0}\right) x_{0}+u_{0} w_{0}+t_{0} h_{0}, \\
\left\|w_{0}-\left[y_{0}-b_{y_{0}}^{3}+R_{\rho_{0}, G\left(b_{y_{0}}^{3}, b_{y_{0}}^{4}\right)}^{A}\left(A\left(b_{y_{0}}^{3}\right)-\rho_{0} F\left(b_{y_{0}}^{1}, b_{y_{0}}^{2}\right)+\rho_{0} g\left(x_{0}\right)\right)\right]\right\| \\
\quad \leq s_{0}\left\|w_{0}-y_{0}-\left(b_{w_{0}}^{3}-b_{y_{0}}^{3}\right)\right\|,
\end{array}\right.
$$

where $b_{y_{0}}^{k} \in S_{k}\left(y_{0}\right)(1 \leq k \leq 4)$, and $e_{0}, h_{0} \in X$ are errors to take into account a possible inexact computation of the proximal point.

Step 2: The sequences $\left\{x_{n}\right\}$ and $\left\{y_{n}\right\}$ are generated by an iterative procedure

$$
\left\{\begin{array}{l}
y_{n}=\left(1-v_{n}\right) x_{n}+v_{n} z_{n}+l_{n} e_{n} ; \\
\left\|z_{n}-\left[x_{n}-b_{x_{n}}^{3}+R_{\rho_{n}, G\left(b_{x_{n}}^{3}, b_{x_{n}}^{4}\right)}^{A, \eta}\left(A\left(b_{x_{n}}^{3}\right)-\rho F\left(b_{x_{n}}^{1}, b_{x_{n}}^{2}\right)+\rho_{n} g\left(x_{n}\right)\right)\right]\right\| \\
\quad \leq p_{n}\left\|z_{n}-x_{n}-\left(b_{z_{n}}^{3}-b_{x_{n}}^{3}\right)\right\|, \\
x_{n+1}=\left(1-u_{n}\right) x_{n}+u_{n} w_{n}+t_{n} h_{n}, \\
\left\|w_{n}-\left[y_{n}-b_{y_{n}}^{3}+R_{\rho_{n}, G\left(b_{y_{n}}, b_{y_{n}}^{4}\right)}^{A, \eta}\left(A\left(b_{y_{n}}^{3}\right)-\rho F\left(b_{y_{n}}^{1}, b_{y_{n}}^{2}\right)+\rho_{n} g\left(y_{n}\right)\right)\right]\right\| \\
\quad \leq s_{n}\left\|w_{n}-y_{n}-\left(b_{w_{n}}^{3}-b_{y_{n}}^{3}\right)\right\|,
\end{array}\right.
$$

where $b_{x_{n}}^{k} \in S_{k}$ and $b_{y_{n}}^{k} \in S_{k}(1 \leq k \leq 4)$, and $e_{n}, h_{n} \in X$ are errors to take into account a possible inexact computation of the proximal point and

$$
\limsup _{n \rightarrow \infty}\left\|e_{n}\right\|=\limsup _{n \rightarrow \infty}\left\|h_{n}\right\|<+\infty \text {. }
$$

By using Nadler [39], we can choose suitable $b_{n}^{k} \in S_{k}\left(x_{n}\right)$ such that

$$
\left\|b_{n-1}^{k}-b_{n}^{k}\right\| \leq\left(1+\frac{1}{n_{1}}\right) \mathbf{h}\left(S_{k}\left(x_{n-1}\right), S_{k}\left(x_{n}\right)\right)
$$

where $\mathbf{h}(\cdot, \cdot)$ is the Hausdorff metric in $\mathrm{CB}(X), n=1,2, \ldots$ 
Remark 5.2 For a suitable choice of the mappings $A, \eta, f, g, F, G, \widehat{S_{k}}, a_{k}$, space $X$, and nonnegative sequences $\left\{u_{n}\right\}_{n=0}^{\infty},\left\{v_{n}\right\}_{n=0}^{\infty},\left\{p_{n}\right\}_{n=0}^{\infty},\left\{s_{n}\right\}_{n=0}^{\infty},\left\{l_{n}\right\}_{n=0}^{\infty},\left\{t_{n}\right\}_{n=0}^{\infty}$ and $\left\{\rho_{n}\right\}_{n=0}^{\infty}$, Algorithm 5.1 can be degenerated to a number of algorithms involving many known algorithms which are due to classes of variational inequalities and variational inclusions $[10,11,30-$ $34,45,47,50,56]$.

Theorem 5.3 Let $X$ be a q-uniformly smooth Banach space. Let $A, f, g: X \rightarrow X ; \eta, N:$ $X \times X \rightarrow X$ be single-valued mappings, and $\eta$ be a $\tau$-Lipschitz continuous mapping, $A$ be an $r$-strongly $\eta$-accretive and $\alpha$-Lipschitz continuous mapping, $f$ be a $\chi$-Lipschitz continuous mapping, and $g$ be a $\varphi$-Lipschitz continuous and $(\psi, \kappa)-S_{3}$-relaxed cocoercive with respect to A mapping, respectively. For $k \in\{1,2,3,4\}$, let $\widehat{S_{k}}: X \rightarrow \mathcal{F}(X)$ be a fuzzy mapping satisfying condition $(*)$ and $S_{k}: X \rightarrow \mathrm{CB}(X)$ be a set-valued mapping induced by the fuzzy mapping $\widehat{S_{k}}$, and suppose that $S_{k}$ is $\mathbf{h}$-Lipschitz continuous with constants $\xi_{k}$ and that $S_{3}$ is $\gamma$-strongly accretive. Let $F: X \times X \rightarrow X$ be $(\mu, v)$-Lipschitz continuous. Let $G(\cdot, t): X \rightarrow 2^{X}$ be a set-valued $(A, \eta)$-accretive mapping for any $t \in X$ and $\operatorname{range}\left(S_{3}\right) \cap \operatorname{dom} G(\cdot, t) \neq \emptyset$, and for any $x, y, z \in X$,

$$
\left\|R_{\rho, G(x,)}^{A, \eta}(z)-R_{\rho, G(y, \cdot)}^{A, \eta}(z)\right\| \leq \delta\|x-y\| .
$$

If nonnegative sequences $\left\{u_{n}\right\}_{n=0}^{\infty},\left\{v_{n}\right\}_{n=0}^{\infty},\left\{p_{n}\right\}_{n=0}^{\infty},\left\{s_{n}\right\}_{n=0}^{\infty},\left\{l_{n}\right\}_{n=0}^{\infty},\left\{t_{n}\right\}_{n=0}^{\infty}$ and $\left\{\rho_{n}\right\}_{n=0}^{\infty}$ are

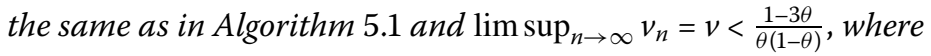

$$
\begin{aligned}
\theta= & \left(1+c_{q} \chi^{q}-q \gamma\right)^{\frac{1}{q}}+\delta \xi_{3}^{q} \\
& +\frac{\tau^{q-1}}{r-m \rho}\left[\rho\left(\mu \xi_{1}+\nu \chi \xi_{2}\right)+\left(\alpha^{q} \xi_{3}^{q}+c_{q} \rho^{q} \varphi^{q}-q \rho \psi+\rho \kappa \alpha^{q} \xi_{1}^{q}\right)^{\frac{1}{q}}\right],
\end{aligned}
$$

then the sequence $\left\{x_{n}\right\}_{n=1}^{\infty}$ generated by perturbed Ishikawa-hybrid quasi-proximal point Algorithm 5.1 converges linearly to $x^{*}$ as

$$
\begin{aligned}
& \left(\frac{1}{3}-\left(1+c_{q} \chi^{q}-q \gamma\right)^{\frac{1}{q}}-\delta \xi_{3}^{q}\right)(r-m \rho) \tau^{q-1} \\
& \quad<\rho\left(\mu \xi_{1}+\nu \chi \xi_{2}\right)+\left(\alpha^{q} \xi_{3}^{q}+c_{q} \rho^{q} \varphi^{q}-q \rho \psi+\rho \kappa \alpha^{q} \xi_{1}^{q}\right)^{\frac{1}{q}},
\end{aligned}
$$

where $c_{q}>0$ is the same as in Lemma 2.8, $\rho \in\left(0, \frac{r}{m}\right)$, and the convergence rate is $\varepsilon=1-u(1-$ $\theta(3+v \theta-v))$, and problem (3.1) has a solution $\left(x^{*}, b^{1 *}, b^{2 *}, b^{3 *}, b^{4 *}\right) \in X^{5}$, where $b^{k *} \in S_{k}\left(x^{*}\right)$ $(1 \leq k \leq 4)$.

Proof Suppose that the sequence $\left\{x_{n}\right\}$ is the sequence generated by perturbed Ishikawahybrid quasi-proximal point Algorithm 5.1, and that $\left(x^{*}, b^{1 *}, b^{2 *}, b^{3 *}, b^{4 *}\right) \in X^{5}$ is a solution of problem (3.1). From Lemma 4.1 and condition $\alpha_{n} \in[0,1)$, we can get

$$
x^{*}=\left(1-u_{n}\right) x^{*}+u_{n}\left(x^{*}-b^{3 *}+R_{\rho_{n}, G\left(b^{3 *}, b^{* *}\right)}^{A, \eta}\left(A\left(b^{3 *}\right)-\rho_{n} F\left(b^{1 *}, f\left(b^{2 *}\right)\right)-\rho_{n} g\left(x^{*}\right)\right)\right),
$$

where $b^{k *} \in S_{k}\left(x^{*}\right)(1 \leq k \leq 4)$.

For all $n \geq 0$ and $b^{k *} \in S_{k}\left(x^{*}\right)(1 \leq k \leq 4)$, set

$$
c_{n+1}=\left(1-u_{n}\right) x_{n}+u_{n}\left(x_{n}-b_{x_{n}}^{3}+R_{\rho_{n}, G\left(b_{x_{n}}^{3}, b_{x_{n}}^{4}\right)}^{A, \eta}\left(A\left(b_{x_{n}}^{3}\right)-\rho_{n} F\left(b_{x_{n}}^{1}, f\left(b_{x_{n}}^{2}\right)\right)-\rho_{n} g\left(x_{n}\right)\right)\right) .
$$


By using (4.9), we find the estimation

$$
\begin{aligned}
&\left\|c_{n+1}-x^{*}\right\| \\
& \leq\left(1-u_{n}\right)\left\|x_{n}-x^{*}\right\|+u_{n}\left\|x^{*}-x_{n}-\left(b^{3 *}-b_{x_{n}}^{3}\right)\right\| \\
& \quad+u_{n} \| R_{\rho_{n}, G\left(b_{x_{n}}^{3}, b_{x_{n}}^{4}\right)}^{A, \eta}\left(A\left(b_{x_{n}}^{3}\right)-\rho_{n} F\left(b_{x_{n}}^{1}, f\left(b_{x_{n}}^{2}\right)\right)-\rho_{n} g\left(x_{n}\right)\right) \\
& \quad-R_{\rho_{n}, G\left(b^{3 *}, b^{4 *}\right)}^{A, \eta}\left(A\left(b^{3 *}\right)-\rho_{n} F\left(b^{1 *}, f\left(b^{2 *}\right)\right)-\rho_{n} g\left(x^{*}\right)\right) \| \\
& \leq\left[\left(1-u_{n}\right)+u_{n} \theta_{n}\right]\left\|x_{n}-x^{*}\right\|,
\end{aligned}
$$

where

$$
\begin{aligned}
\theta_{n}= & \left(1+c_{q} \chi^{q}-q \gamma\right)^{\frac{1}{q}}+\delta \xi_{3}^{q}+\left(1+c_{q} \chi^{q}-q \gamma\right)^{\frac{1}{q}} \\
& +\frac{\tau^{q-1}}{r-m \rho_{n}}\left[\rho_{n}\left(\mu \xi_{1}+v \chi \xi_{2}\right)+\left(\alpha^{q} \xi_{3}^{q}+c_{q} \rho_{n}^{q} \varphi^{q}-q \rho_{n} \psi+\rho_{n} \kappa \alpha^{q} \xi_{1}^{q}\right)^{\frac{1}{q}}\right] .
\end{aligned}
$$

Since $x_{n+1}=\left(1-u_{n}\right) x_{n}+u_{n} w_{n}+t_{n} h_{n},(5.1)$ and (4.8)-(4.9) so that $x_{n+1}-x_{n}=u_{n}\left(w_{n}-x_{n}\right)+t_{n} h_{n}$ and

$$
\begin{aligned}
\| x_{n+1} & -c_{n+1} \| \\
\leq & \|\left(1-u_{n}\right) x_{n}+u_{n} w_{n}+t_{n} h_{n} \\
& -\left[\left(1-u_{n}\right) x_{n}+u_{n}\left(x_{n}-b_{x_{n}}^{3}+R_{\rho_{n}, G\left(b_{x_{n}}^{3}, b_{x_{n}}^{4}\right)}^{A, \eta}\left(A\left(b_{x_{n}}^{3}\right)\right.\right.\right. \\
& \left.\left.\left.-\rho_{n} F\left(b_{x_{n}}^{1}, f\left(b_{x_{n}}^{2}\right)\right)-\rho_{n} g\left(x_{n}\right)\right)\right)\right] \| \\
\leq & u_{n} \|\left[y_{n}-b_{y_{n}}^{3}+R_{\rho_{n}, G\left(b_{y_{n}}^{3}, b_{y_{n}}^{4}\right)}^{A, \eta}\left(A\left(b_{y_{n}}^{3}\right)-\rho_{n} F\left(b_{y_{n}}^{1}, f\left(b_{y_{n}}^{2}\right)\right)-\rho_{n} g\left(y_{n}\right)\right)\right] \\
& -\left[\left(1-u_{n}\right) x_{n}+u_{n}\left(x_{n}-b_{x_{n}}^{3}+R_{\rho_{n}, G\left(b_{x_{n}}^{3}, b_{x_{n}}^{4}\right)}^{A, \eta}\left(A\left(b_{x_{n}}^{3}\right)\right.\right.\right. \\
& \left.\left.\left.-\rho_{n} F\left(b_{x_{n}}^{1}, f\left(b_{x_{n}}^{2}\right)\right)-\rho_{n} g\left(x_{n}\right)\right)\right)\right] \| \\
& +u_{n} \| w_{n}-\left[y_{n}-b_{y_{n}}^{3}+R_{\rho_{n}, G\left(b_{y_{n}}^{3}, b_{y_{n}}^{4}\right)}^{A, \eta}\left(A\left(b_{y_{n}}^{3}\right)\right.\right. \\
& \left.\left.-\rho_{n} F\left(b_{y_{n}}^{1}, f\left(b_{y_{n}}^{2}\right)\right)-\rho_{n} g\left(y_{n}\right)\right)\right]\left\|+t_{n}\right\| h_{n} \| \\
\leq & u_{n} s_{n}\left\|w_{n}-y_{n}-\left(b_{w_{n}}^{3}-b_{y_{n}}^{3}\right)\right\|+u_{n} \theta_{n}\left\|x_{n}-y_{n}\right\|+t_{n}\left\|h_{n}\right\| \\
\leq & u_{n} s_{n}\left(1+c_{q} \xi_{3}^{q}-q \gamma\right)^{\frac{1}{q}}\left\|w_{n}-y_{n}\right\|+u_{n} \theta_{n}\left\|x_{n}-y_{n}\right\|+t_{n}\left\|h_{n}\right\| .
\end{aligned}
$$

Next, we calculate

$$
\begin{aligned}
& \left\|x_{n+1}-x^{*}\right\| \\
& \leq\left\|c_{n+1}-x^{*}\right\|+\left\|x_{n+1}-c_{n+1}\right\| \\
& \leq\left\|c_{n+1}-x^{*}\right\|+u_{n} s_{n}\left(1+c_{q} \xi_{3}^{q}-q \gamma\right)^{\frac{1}{q}}\left\|w_{n}-y_{n}\right\|+u_{n} \theta_{n}\left\|x_{n}-y_{n}\right\|+t_{n}\left\|h_{n}\right\| \\
& \leq\left\|c_{n+1}-x^{*}\right\|+u_{n} s_{n}\left(1+c_{q} \xi_{3}^{q}-q \gamma\right)^{\frac{1}{q}}\left(\left\|w_{n}-x_{n}\right\|+\left\|y_{n}-x_{n}\right\|\right) \\
& \quad+u_{n} \theta_{n}\left\|x_{n}-y_{n}\right\|+t_{n}\left\|h_{n}\right\|
\end{aligned}
$$




$$
\begin{aligned}
\leq & \left\|c_{n+1}-x^{*}\right\|+s_{n}\left(1+c_{q} \xi_{3}^{q}-q \gamma\right)^{\frac{1}{q}} u_{n}\left\|w_{n}-x_{n}\right\| \\
& +u_{n}\left(s_{n}\left(1+c_{q} \xi_{3}^{q}-q \gamma\right)^{\frac{1}{q}}+\theta_{n}\right)\left\|y_{n}-x_{n}\right\|+t_{n}\left\|h_{n}\right\| \\
\leq & {\left[\left(1-u_{n}\right)+u_{n} \theta_{n}\right]\left\|x_{n}-x^{*}\right\|+s_{n}\left(1+c_{q} \xi_{3}^{q}-q \gamma\right)^{\frac{1}{q}}\left(\left\|x_{n+1}-x_{n}\right\|+t_{n}\left\|h_{n}\right\|\right) } \\
& +u_{n}\left(s_{n}\left(1+c_{q} \xi_{3}^{q}-q \gamma\right)^{\frac{1}{q}}+\theta_{n}\right)\left\|y_{n}-x_{n}\right\|+t_{n}\left\|h_{n}\right\| \\
\leq & {\left[\left(1-u_{n}\right)+u_{n} \theta_{n}\right]\left\|x_{n}-x^{*}\right\|+s_{n}\left(1+c_{q} \xi_{3}^{q}-q \gamma\right)^{\frac{1}{q}}\left\|x_{n+1}-x_{n}\right\| } \\
& +u_{n}\left(s_{n}\left(1+c_{q} \xi_{3}^{q}-q \gamma\right)^{\frac{1}{q}}+\theta_{n}\right)\left\|y_{n}-x_{n}\right\| \\
& +\left(s_{n}\left(1+c_{q} \xi_{3}^{q}-q \gamma\right)^{\frac{1}{q}}+1\right) t_{n}\left\|h_{n}\right\| \\
\leq & {\left[\left(1-u_{n}\right)+u_{n} \theta_{n}\right]\left\|x_{n}-x^{*}\right\|+s_{n}\left(1+c_{q} \xi_{3}^{q}-q \gamma\right)^{\frac{1}{q}}\left(\left\|x_{n+1}-x^{*}\right\|+\left\|x^{*}-x_{n}\right\|\right) } \\
& +u_{n}\left(s_{n}\left(1+c_{q} \xi_{3}^{q}-q \gamma\right)^{\frac{1}{q}}+\theta_{n}\right)\left(\left\|y_{n}-x^{*}\right\|+\left\|x^{*}-x_{n}\right\|\right) \\
& +\left(s_{n}\left(1+c_{q} \xi_{3}^{q}-q \gamma\right)^{\frac{1}{q}}+1\right) t_{n}\left\|h_{n}\right\| \\
\leq & {\left[\left(1-u_{n}\right)+u_{n} \theta_{n}+s_{n}\left(1+c_{q} \xi_{3}^{q}-q \gamma\right)^{\frac{1}{q}}+u_{n}\left(s_{n}\left(1+c_{q} \xi_{3}^{q}-q \gamma\right)^{\frac{1}{q}}+\theta_{n}\right)\right]\left\|x_{n}-x^{*}\right\| } \\
& +s_{n}\left(1+c_{q} \xi_{3}^{q}-q \gamma\right)^{\frac{1}{q}}\left\|x_{n+1}-x^{*}\right\|+u_{n}\left(s_{n}\left(1+c_{q} \xi_{3}^{q}-q \gamma\right)^{\frac{1}{q}}+\theta_{n}\right)\left\|y_{n}-x^{*}\right\| \\
& +\left(s_{n}\left(1+c_{q} \xi_{3}^{q}-q \gamma\right)^{\frac{1}{q}}+1\right) t_{n}\left\|h_{n}\right\| .
\end{aligned}
$$

This implies that

$$
\begin{aligned}
& \left\|x_{n+1}-x^{*}\right\| \\
& \leq \frac{u_{n}\left(s_{n}\left(1+c_{q} \xi_{3}^{q}-q \gamma\right)^{\frac{1}{q}}+\theta_{n}\right)}{1-s_{n}\left(1+c_{q} \xi_{3}^{q}-q \gamma\right)^{\frac{1}{q}}}\left\|y_{n}-x^{*}\right\|+\frac{\left(s_{n}\left(1+c_{q} \xi_{3}^{q}-q \gamma\right)^{\frac{1}{q}}+1\right) t_{n}}{1-s_{n}\left(1+c_{q} \xi_{3}^{q}-q \gamma\right)^{\frac{1}{q}}}\left\|h_{n}\right\| \\
& \quad+\frac{\left[\left(1-u_{n}\right)+u_{n} \theta_{n}+s_{n}\left(1+c_{q} \xi_{3}^{q}-q \gamma\right)^{\frac{1}{q}}+u_{n}\left(s_{n}\left(1+c_{q} \xi_{3}^{q}-q \gamma\right)^{\frac{1}{q}}+\theta_{n}\right)\right]}{1-s_{n}\left(1+c_{q} \xi_{3}^{q}-q \gamma\right)^{\frac{1}{q}}} \\
& \quad \times\left\|x_{n}-x^{*}\right\| .
\end{aligned}
$$

Let

$$
x^{*}=\left(1-v_{n}\right) x^{*}+v_{n}\left(x^{*}-b^{3 *}+R_{\rho_{n}, G\left(b^{3 *}, b^{4 *}\right)}^{A, \eta}\left(A\left(b^{3 *}\right)-\rho_{n} F\left(b^{1 *}, f\left(b^{2 *}\right)\right)-\rho_{n} g\left(x^{*}\right)\right)\right) .
$$

For all $n \geq 0$, set

$$
d_{n}=\left(1-v_{n}\right) x_{n}+v_{n}\left(x_{n}-b_{x_{n}}^{3}+R_{\rho_{n}, G\left(b_{x_{n}}^{3}, b_{x_{n}}^{4}\right)}^{A, \eta}\left(A\left(b_{x_{n}}^{3}\right)-\rho_{n} F\left(b_{x_{n}}^{1}, f\left(b_{x_{n}}^{2}\right)\right)-\rho_{n} g\left(x_{n}\right)\right)\right) .
$$

For the same reason,

$$
\left\|d_{n}-x^{*}\right\| \leq\left(\left(1-v_{n}\right)+v_{n} \theta_{n}\right)\left\|x_{n}-x^{*}\right\|,
$$


and by using $y_{n}=\left(1-v_{n}\right) x_{n}+v_{n} z_{n}+l_{n} e_{n}$ in (5.1), the following holds:

$$
\begin{aligned}
\| y_{n}- & x^{*} \| \\
\leq & \left\|d_{n}-x^{*}\right\|+\left\|y_{n}-d_{n}\right\| \\
\leq & \left(\left(1-v_{n}\right)+v_{n} \theta_{n}\right)\left\|x_{n}-x^{*}\right\|+\left[\left(1-v_{n}\right) x_{n}+v_{n} z_{n}+l_{n} e_{n}\right. \\
& -\left(\left(1-v_{n}\right) x_{n}+v_{n}\left(x_{n}-b_{x_{n}}^{3}+R_{\rho_{n}, G\left(b_{x_{n}}^{3}, b_{x_{n}}^{4}\right)}^{A, \eta}\left(A\left(b_{x_{n}}^{3}\right)\right.\right.\right. \\
& \left.\left.\left.\left.-\rho_{n} F\left(b_{x_{n}}^{1}, f\left(b_{x_{n}}^{2}\right)\right)-\rho_{n} g\left(x_{n}\right)\right)\right)\right)\right] \\
\leq & \left(\left(1-v_{n}\right)+v_{n} \theta_{n}\right)\left\|x_{n}-x^{*}\right\|+l_{n}\left\|e_{n}\right\| \\
& +v_{n}\left\|z_{n}-\left(x_{n}-b_{x_{n}}^{3}+R_{\rho_{n}, G\left(b_{x_{n}}^{3}, b_{x_{n}}^{4}\right)}^{A, \eta}\left(A\left(b_{x_{n}}^{3}\right)-\rho_{n} F\left(b_{x_{n}}^{1}, f\left(b_{x_{n}}^{2}\right)\right)-\rho_{n} g\left(x_{n}\right)\right)\right)\right\| \\
\leq & \left(\left(1-v_{n}\right)+v_{n} \theta_{n}\right)\left\|x_{n}-x^{*}\right\|+l_{n}\left\|e_{n}\right\|+v_{n} p_{n}\left\|z_{n}-x_{n}-\left(b_{z_{n}}^{3}-b_{x_{n}}^{3}\right)\right\| \\
\leq & \left(\left(1-v_{n}\right)+v_{n} \theta_{n}\right)\left\|x_{n}-x^{*}\right\|+l_{n}\left\|e_{n}\right\|+v_{n} p_{n}\left(1+c_{q} \xi_{3}^{q}-q \gamma\right)^{\frac{1}{q}}\left\|z_{n}-x_{n}\right\| \\
\leq & \left(\left(1-v_{n}\right)+v_{n} \theta_{n}\right)\left\|x_{n}-x^{*}\right\|+l_{n}\left\|e_{n}\right\| \\
& +p_{n}\left(1+c_{q} \xi_{3}^{q}-q \gamma\right)^{\frac{1}{q}}\left(\left\|y_{n}-x_{n}\right\|+l_{n}\left\|e_{n}\right\|\right) \\
\leq & \left(\left(1-v_{n}\right)+v_{n} \theta_{n}\right)\left\|x_{n}-x^{*}\right\|+p_{n}\left(1+c_{q} \xi_{3}^{q}-q \gamma\right)^{\frac{1}{q}}\left(\left\|y_{n}-x^{*}\right\|+\left\|x^{*}-x_{n}\right\|\right) \\
& +\left(1+p_{n}\left(1+c_{q} \xi_{3}^{q}-q \gamma\right)^{\frac{1}{q}}\right) l_{n}\left\|e_{n}\right\| .
\end{aligned}
$$

Furthermore,

$$
\begin{aligned}
\left\|y_{n}-x^{*}\right\| \leq & \frac{\left(1-v_{n}\right)+v_{n} \theta_{n}+p_{n}\left(1+c_{q} \xi_{3}^{q}-q \gamma\right)^{\frac{1}{q}}}{1-p_{n}\left(1+c_{q} \xi_{3}^{q}-q \gamma\right)^{\frac{1}{q}}}\left\|x_{n}-x^{*}\right\| \\
& +\frac{\left(1+p_{n}\left(1+c_{q} \xi_{3}^{q}-q \gamma\right)^{\frac{1}{q}}\right) l_{n}}{1-p_{n}\left(1+c_{q} \xi_{3}^{q}-q \gamma\right)^{\frac{1}{q}}} l_{n}\left\|e_{n}\right\| .
\end{aligned}
$$

Combining (5.7)-(5.10), we have

$$
\begin{aligned}
\| x_{n+1} & -x^{*} \| \\
\leq & {\left[\frac{u_{n}\left(s_{n}\left(1+c_{q} \xi_{3}^{q}-q \gamma\right)^{\frac{1}{q}}+\theta_{n}\right)}{1-s_{n}\left(1+c_{q} \xi_{3}^{q}-q \gamma\right)^{\frac{1}{q}}} \times \frac{\left(1-v_{n}\right)+v_{n} \theta_{n}+p_{n}\left(1+c_{q} \xi_{3}^{q}-q \gamma\right)^{\frac{1}{q}}}{1-p_{n}\left(1+c_{q} \xi_{3}^{q}-q \gamma\right)^{\frac{1}{q}}}\right.} \\
& \left.+\frac{\left[\left(1-u_{n}\right)+u_{n} \theta_{n}+s_{n}\left(1+c_{q} \xi_{3}^{q}-q \gamma\right)^{\frac{1}{q}}+u_{n}\left(s_{n}\left(1+c_{q} \xi_{3}^{q}-q \gamma\right)^{\frac{1}{q}}+\theta_{n}\right)\right]}{1-s_{n}\left(1+c_{q} \xi_{3}^{q}-q \gamma\right)^{\frac{1}{q}}}\right]\left\|x_{n}-x^{*}\right\| \\
& \times \frac{\left(s_{n}\left(1+c_{q} \xi_{3}^{q}-q \gamma\right)^{\frac{1}{q}}+1\right) t_{n}}{1-s_{n}\left(1+c_{q} \xi_{3}^{q}-q \gamma\right)^{\frac{1}{q}}}\left\|h_{n}\right\| \\
& +\frac{\left(1+p_{n}\left(1+c_{q} \xi_{3}^{q}-q \gamma\right)^{\frac{1}{q}}\right) l_{n}}{1-p_{n}\left(1+c_{q} \xi_{3}^{q}-q \gamma\right)^{\frac{1}{q}}} l_{n}\left\|e_{n}\right\| .
\end{aligned}
$$


By (5.4) and the conditions

$$
\begin{aligned}
& \lim _{n \rightarrow \infty} p_{n}=\lim _{n \rightarrow \infty} s_{n}=\lim _{n \rightarrow \infty} l_{n}=\lim _{n \rightarrow \infty} t_{n}=0, \\
& u=\limsup _{n \rightarrow \infty} u_{n}<1, \quad v=\limsup _{n \rightarrow \infty} v_{n}<\frac{1-3 \theta}{\theta(1-\theta)}, \quad \rho_{n} \uparrow \rho \leq \infty, \\
& \limsup _{n \rightarrow \infty}\left\|e_{n}\right\|=\limsup _{n \rightarrow \infty}\left\|h_{n}\right\|<+\infty,
\end{aligned}
$$

we can see

$$
\begin{aligned}
\left\|x_{n+1}-x^{*}\right\| & \leq[u \theta(1-v(1-\theta))+(1-u(1-2 \theta))]\left\|x_{n}-x^{*}\right\| \\
& =\varepsilon\left\|x_{n}-x^{*}\right\|,
\end{aligned}
$$

where $\varepsilon=1-u(1-\theta(3+v \theta-v)) \in(0,1)$ for $v<\frac{1-3 \theta}{\theta(1-\theta)}$; and

$$
\begin{aligned}
\theta= & \lim _{n \rightarrow \infty} \theta_{n} \\
= & \left(1+c_{q} \chi^{q}-q \gamma\right)^{\frac{1}{q}}+\delta \xi_{3}^{q} \\
& +\frac{\tau^{q-1}}{r-m \rho}\left[\rho\left(\mu \xi_{1}+\nu \chi \xi_{2}\right)+\left(\alpha^{q} \xi_{3}^{q}+c_{q} \rho^{q} \varphi^{q}-q \rho \psi+\rho \kappa \alpha^{q} \xi_{1}^{q}\right)^{\frac{1}{q}}\right],
\end{aligned}
$$

and the convergence rate is $\varepsilon$.

Therefore, the sequence $\left\{x_{n}\right\}_{n=1}^{\infty}$ generated by Algorithm 5.1 converges linearly to a solution $x^{*}$ with convergence rate $\varepsilon$ in a Banach space.

Let $x_{n} \rightarrow x^{*}$ as $n \rightarrow \infty$. For any $k \in\{1,2,3,4\}$, by the $\mathbf{h}$-Lipschitz continuity of $S_{k}(x)$ $(1 \leq k \leq 4)$ with constants $\xi_{k}$, we obtain

$$
\left\|b_{n+1}^{k}-b_{n}^{k}\right\| \leq\left(1+n^{-1}\right) D\left(S_{k}\left(x_{n+1}\right), S_{k}\left(x_{n}\right)\right) \leq \xi_{k}\left(1+n^{-1}\right)\left\|x_{n+1}-x_{n}\right\| .
$$

It follows that $\left\{b_{n}^{k}\right\}_{n=1}^{\infty}$ are also Cauchy sequences in $X$. We can assume that $b_{n}^{k} \rightarrow b^{k *}$. Note that $b_{n}^{k} \in S_{k}\left(x_{n}\right)$, we have

$$
\begin{aligned}
d\left(b^{k *}, S\left(x^{*}\right)\right) & \leq\left\|b^{k *}-b_{n}^{k}\right\|+d\left(b_{n}^{k}, S\left(x^{*}\right)\right) \\
& \leq\left\|b^{k *}-b_{n}^{k}\right\|+D\left(S\left(x_{n}\right), S\left(x^{*}\right)\right) \\
& \leq\left\|b^{k *}-b_{n}^{k}\right\|+\xi_{k}\left\|x_{n}-x^{*}\right\| \rightarrow 0 \quad(n \rightarrow \infty) .
\end{aligned}
$$

Hence $d\left(b^{k *}, S_{k}\left(x^{*}\right)\right)=0$ and therefore $b^{k *} \in S_{k}\left(x^{*}\right)$.

By the Lipschitz continuity of $S_{k}$ and Lemma 2.7, condition (5.4), we have

$$
x^{*}=(1-\lambda) x^{*}+\lambda\left(x^{*}-b^{3 *}+R_{\rho_{n}, G\left(b^{3 *}, b^{4 *}\right)}^{A * \eta}\left(A\left(b^{3 *}\right)-\rho_{n} F\left(b^{1 *}, f\left(b^{2 *}\right)\right)-\rho_{n} g\left(x^{*}\right)\right)\right)
$$

for any $0<\lambda<1$. By Lemma 4.1, we know that problem (3.1) has a solution $\left(x^{*}, b^{1 *}, b^{2 *}, b^{3 *}\right.$, $\left.b^{4 *}\right) \in X^{5}$, where $b^{k *} \in S_{k}\left(x^{*}\right)(1 \leq k \leq 4)$. This completes the proof.

Remark 5.4 For a suitable choice of the mappings $A, \eta, f, g, F, G, \widehat{S_{k}}(1 \leq k \leq 4)$, we can obtain several known results $[1,3-11,30-34,45,47,56]$ as special cases of Theorem 5.3 . 


\section{Author details}

'Institute of Applied Mathematics Research, Chongqing University of Posts and Telecommunications, Chongqing, 400065, China. ${ }^{2}$ Institute of Nonlinear Analysis Research, Changjiang Normal University, Chongqing Fuling, 400803, China.

\section{Acknowledgements}

This work was supported by the Mathematical Tianyuan Foundation of China (Grant No. 11126087), the National Natural Science Foundation of China (Grant No. 11201512) and the Natural Science Foundation Project of CQ CSTC (cstc2012jjA00001).

\section{Received: 9 May 2013 Accepted: 26 September 2013 Published: 08 Nov 2013}

\section{References}

1. Di Bella, B: An existence theorem for a class of inclusions. Appl. Math. Lett. 13(3), 15-19 (2000)

2. Huang, NJ, Tang, YY, Liu, YP: Some new existence theorems for nonlinear inclusion with an application. Nonlinear Funct. Anal. Appl. 6, 341-350 (2001)

3. Jeong, JU: Generalized set-valued variational inclusions and resolvent equations in Banach spaces. Comput. Math Appl. 47, 1241-1247 (2004)

4. Ding, XP, Luo, CL: Perturbed proximal point algorithms for generalized quasi-variational-like inclusions. J. Comput. Appl. Math. 210, 153-165 (2000)

5. Verma, RU: Approximation-solvability of a class of A-monotone variational inclusion problems. J. KSIAM 8(1), 55-66 (2004)

6. Huang, NJ: Nonlinear implicit quasi-variational inclusions involving generalized $m$-accretive mappings. Arch. Inequal. Appl. 2(4), 413-425 (2004)

7. Fang, YP, Huang, NJ: H-accretive operators and resolvent operator technique for solving variational inclusions in Banach spaces. Appl. Math. Lett. 17(6), 647-653 (2004)

8. Lan, $\mathrm{HY}$, Cho, YJ, Verma, RU: On nonlinear relaxed cocoercive inclusions involving $(A, \eta)$-accretive mappings in Banach spaces. Comput. Math. Appl. 51, 1529-1538 (2006)

9. Fang, YP, Huang, NJ, Thompson, HB: A new system of variational inclusions with $(H, \eta)$-monotone operators in Hilbert spaces. Comput. Math. Appl. 49, 365-374 (2005)

10. Zhang, QB, Zhanging, XP, Cheng, CZ: Resolvent operator technique for solving generalized implicit variational-like inclusions in Banach space. J. Math. Anal. Appl. 20, 216-221 (2007)

11. Li, HG: Perturbed Ishikawa iterative algorithm and stability for nonlinear mixed quasi-variational inclusions involving $(A, \eta)$-accretive mappings. Adv. Nonlinear Var. Inequal. 11(1), 41-50 (2008)

12. Zadeh, LA: Fuzzy sets. Inf. Control 8, 338-353 (1965)

13. El Ghoul, M, El-Zohny, H, Radwan, S: Fuzzy incidence matrix of fuzzy simplicial complexes and its folding. Chaos Solitons Fractals 13, 33-1827 (2002)

14. El Sayied, HK: Study on generalized convex fuzzy bodies. Appl. Math. Comput. 152, 1-8 (2004)

15. Kaleva, O, Seikkala, S: On fuzzy metric spaces. Fuzzy Sets Syst. 12, 29-215 (1984)

16. Park, JH: Intuitionistic fuzzy metric spaces. Chaos Solitons Fractals 22, 46-1039 (2004)

17. Adibi, $\mathrm{H}, \mathrm{Cho}, \mathrm{YJ}, \mathrm{O}$ 'Regan, D, Saadati, R: Common fixed point theorems in L-fuzzy metric spaces. Appl. Math. Comput. $182,8-820(2006)$

18. Alaca, C, Turkoglu, D, Yildiz, C: Fixed points in intuitionistic fuzzy metric spaces. Chaos Solitons Fractals 29, 8-1073 (2006)

19. Chang, SS, Cho, YJ, Lee, BS, Jung, JS, Kang, SM: Coincidence point and minimization theorems in fuzzy metric spaces. Fuzzy Sets Syst. 88, 28-119 (1997)

20. Gregori, V, Sapena, A: On fixed point theorem in fuzzy metric spaces. Fuzzy Sets Syst. 125, 52-245 (2002)

21. Saadati, R, Razani, A, Adibi, H: A common fixed point theorems in L-fuzzy metric spaces. Chaos Solitons Fractals 33, 63-358 (2007)

22. Diamond, P, Kloeden, P, Pokrovskii, A: Absolute retracts and a general fixed point theorem for fuzzy sets. Fuzzy Sets Syst. 86, 80-377 (1997)

23. Kaleva, O: On the convergence of fuzzy sets. Fuzzy Sets Syst. 17, $53-65$ (1985)

24. Diamond, P, Kloeden, P: Characterization of compact subsets of fuzzy sets. Fuzzy Sets Syst. 29, 8-341 (1989)

25. Puri, ML, Ralescu, DA: The concept of normality for fuzzy random variables. Ann. Probab. 13, 9-1373 (1985)

26. Diamond, P, Kloeden, P: Metric spaces of fuzzy sets. Fuzzy Sets Syst. 35, 9-241 (1990)

27. Klement, EP, Puri, ML, Ralescu, DA: Limit theorems for fuzzy random variables. Proc. R. Soc. Lond. Ser. A 407, 82-171 (1986)

28. El Naschie, MS: On the uncertainty of Cantorian geometry and two-slit experiment. Chaos Solitons Fractals 9, 29-517 (1998)

29. El Naschie, MS: On an eleven dimensional E-infinity fractal spacetime theory. Int. J. Nonlinear Sci. Numer. Simul. 7, 9-407 (2006)

30. Chang, SS, Zhou, HY: On variational inequalities for fuzzy mappings. Fuzzy Sets Syst. 32, 359-367 (1989)

31. Chang, SS, Huang, NJ: Generalized complementarity problem for fuzzy mappings. Fuzzy Sets Syst. 55, 227-234 (1993)

32. Ding, XP, Jong, YP: A new class of generalized nonlinear implicit quasivariational inclusions with fuzzy mappings. J. Comput. Appl. Math. 138, 243-257 (2002)

33. Jin, MM: Perturbed proximal point algorithm for general quasi-variational inclusions with fuzzy set-valued mappings. ORTrans. 9(3), 31-38 (2005)

34. Li, HG: Iterative algorithm for a new class of generalized nonlinear fuzzy set-valued variational inclusions involving $(H, \eta)$-monotone mappings. Adv. Nonlinear Var. Inequal. 10(1), 89-100 (2007)

35. Eckstein, J, Bertsekas, DP: On the Douglas-Rachford splitting method and the proximal point algorithm for maximal monotone operators. Math. Program. 55, 293-318 (1992)

36. Verma, RU: A hybrid proximal point algorithm based on the $(A, \eta)$-maximal monotonicity framework. Appl. Math. Lett. $21,142-147(2008)$ 
37. Li, HG: Approximate algorithm of solutions for general nonlinear fuzzy multivalued quasi-variational inclusions with $(G, \eta)$-monotone mappings. Nonlinear Funct. Anal. Appl. 13(2), 277-289 (2008)

38. Xu, HK: Inequalities in Banach spaces with applications. Nonlinear Anal. 16(12), 1127-1138 (1991)

39. Nadler, SB: Multivalued contraction mappings. Pac. J. Math. 30, 475-488 (1969)

40. Agarwal, RP, Huang, NJ, Cho, YJ: Generalized nonlinear mixed implicit quasi-variational inclusions. Appl. Math. Lett. 13(6), 19-24 (2000)

41. Weng, XL: Fixed point iteration for local strictly pseudo-contractive mapping. Proc. Am. Math. Soc. 113, 727-732 (1991)

42. Jin, MM: Perturbed algorithm and stability for strongly nonlinear quasi-variational inclusion involving $\mathrm{H}$-accretive operators. Math. Inequal. Appl. 9(4), 771-779 (2006)

43. Huang, NJ, Fang, YP: Generalized m-accretive mappings in Banach spaces. J. Sichuan Univ. 38(4), 591-592 (2001)

44. Shim, SH, Kang, SM, Huang, NJ, Yao, JC: Perturbed iterative algorithms with errors for completely generalized strongly nonlinear implicit variational-like inclusions. J. Inequal. Appl. 5(4), 381-395 (2000)

45. Chang, SS, Cho, YJ, Zhou, HY: Iterative Methods for Nonlinear Operator Equations in Banach Spaces. Nova Sci. Publ., New York (2002)

46. Agarwal, RP, Cho, YJ, Huang, NJ: Sensitivity analysis for strongly nonlinear quasi-variations. Appl. Math. Lett. 13, 19-24 (2000)

47. Li, HG, Xu, AJ, Jin, MM: A Ishikawa-hybrid proximal point algorithm for nonlinear set-valued inclusions problem based on $(A, \eta)$-accretive framework. Fixed Point Theory Appl. 2010, Article ID 501293 (2010). doi:10.1155/2010/501293

48. Alimohammady, M, Balooee, J, Cho, YJ, Roohi, M: New perturbed finite step iterative algorithms for a system of extended generalized nonlinear mixed-quasi variational inclusions. Comput. Math. Appl. 60, 2953-2970 (2010)

49. Yao, Y, Cho, YJ, Liou, Y: Iterative algorithms for variational inclusions, mixed equilibrium problems and fixed point problems approach to optimization problems. Cent. Eur. J. Math. 9, 640-656 (2011)

50. Yao, Y, Cho, YJ, Liou, Y: Algorithms of common solutions for variational inclusions, mixed equilibrium problems and fixed point problems. Eur. J. Oper. Res. 212, 242-250 (2011)

51. Cho, YJ, Reza, S, Damjanovi, B: On convergence of Ishikawa's type iteration to a common fixed point in L-fuzzy metric spaces. J. Comput. Anal. Appl. 12(1A), 76-82 (2010)

52. Li, HG: Nonlinear inclusion problems for ordered RME set-valued mappings in ordered Hilbert spaces. Nonlinear Funct. Anal. Appl. 16(1), 1-8 (2011)

53. Li, HG: Nonlinear inclusion problem involving $(\alpha, \lambda)$-NODM set-valued mappings in ordered Hilbert space. Appl. Math. Lett. 25, 1384-1388 (2012)

54. Pan, XB, Li, HG, Xu, AJ: The over-relaxed a-proximal point algorithm for general nonlinear mixed set-valued inclusion framework. Fixed Point Theory Appl. 2011, Article ID 840978 (2011). doi:10.1155/2011/840978

55. $L i, H-G, X u, A-J: A$ new class of generalized nonlinear random set-valued quasi-variational inclusion system with random nonlinear $\left(\mathbf{A}_{i \omega}, \eta_{i \omega}\right)$-accretive mappings in q-uniformly smooth Banach spaces. Nonlinear Anal. Forum 15 001-020 (2010)

56. Li, HG, Qiu, M: Ishikawa-hybrid proximal point algorithm for NSVI system. Fixed Point Theory Appl. 2012, 195 (2012). doi:10.1186/1687-1812-2012-195

10.1186/1687-1812-2013-281

Cite this article as: Li et al.: Perturbed Ishikawa-hybrid quasi-proximal point algorithm with accretive mappings for a fuzzy system. Fixed Point Theory and Applications 2013, 2013:281

\section{Submit your manuscript to a SpringerOpen ${ }^{\circ}$ journal and benefit from:}

- Convenient online submission

Rigorous peer review

- Immediate publication on acceptance

- Open access: articles freely available online

- High visibility within the field

- Retaining the copyright to your article 